\title{
Turismo e Trabalho: Uma Análise do Destino Religioso Santa Cruz - RN
}

\section{Tourism and Job: an analysis of Religious Destination Santa Cruz-RN}

\author{
Turismo y empleo: Un Análisis de Destino Religioso, Santa Cruz-RN
}

\author{
Aline Mayara Marinho Xavier da Silva ${ }^{1}$ \\ Rodrigo Cardoso da Silva ${ }^{2}$
}

\begin{abstract}
Resumo: O discurso sobre o turismo nas últimas duas décadas incorporou algumas prerrogativas na sociedade brasileira, dentre elas destaca-se: indutor do desenvolvimento econômico, geradora de emprego e de renda, e mitigadora das desigualdades sociais. Tais elementos apresentam-se como ideias apuradas na mídia e ratificadas pelas as políticas públicas de turismo. A problemática que norteia esta pesquisa baseia-se na identificação de como e onde estão sendo criadas as oportunidades de empregos e ocupações advindas da atividade turística. O objetivo geral é elucidar a relação do turismo e a criação de empregos formais e informais em Santa Cruz, município localizado no interior do estado do Rio Grande do Norte. A metodologia utilizada foi predominantemente qualitativa, tendo sido realizada, no primeiro momento, entrevistas com os proprietários de empreendimentos do setor turístico, em seguida, aplicou-se um questionário com os ambulantes (trabalhadores) no principal atrativo turístico. Os principais resultados apontaram que a criação de empregos no município está diretamente relacionada ao perfil de necessidade do visitante do turismo religioso, nesse caso, o setor de restauração. Não Obstante, o setor hoteleiro não veio a ser incrementado de forma significativa pela inserção da atividade do turismo religioso.
\end{abstract}

Palavras-Chave: Turismo; Destino Religioso; Trabalho; Informalidade.

Abstract: The speech on tourism in the last two decades has incorporated some prerogatives in brazilian society, among them stands out: inductor of economic development, employment and income-generating, and mitigation of social inequalities. Such elements are accurate ideas in the media, and ratified by public tourism policies. The question that guides this research is based on the identification of how and where are being created opportunities for jobs and occupations coming tourist activity. The general objective is to elucidate the relationship between tourism and the creation of formal and informal jobs in Santa Cruz, municipality located in the State of Rio Grande do Norte. The methodology used was predominantly qualitative, having been held, the first interviews with the owners of enterprises of the tourism sector, and after applied a questionnaire with the work-people in the main tourist attraction. The main results showed that job creation in the city is directly related to the profile of need the visitor of the religious tourism,

\footnotetext{
${ }^{1}$ Mestradanda em turismo (UFRN/PPGTUR), Bacharel em turismo (UFRN). E-mail: alinemayarmarinho@hotmail.com.

${ }^{2}$ Doutorando em turismo (UFRN/PPGTUR), Mestre em Turismo (UFRN/UFRN), Bacharel em Turismo (UFRN/CERES). E-mail: drigorcs@ @otmail.com
} 
in this case the catering sector Nevertheless, the hotel sector was not significantly increased by the insertion of the activity of religious tourism.

Keywords : Tourism; Religious Destination; Job; Informality.

Resumen: El discurso sobre el turismo en las dos últimas décadas ha incorporado algunas prerrogativas en la sociedad brasileña, entre ellos destaca: inductor del desarrollo económico, empleo y generación de ingresos y reducción de las desigualdades sociales. Tales elementos son ideas precisas en los medios de comunicación y ratificaron por las políticas públicas de turismo. La pregunta que guía que esta investigación se basa en la identificación de cómo y dónde se están creando oportunidades de empleos y ocupaciones que la actividad turística. El objetivo general es para aclarar la relación entre el turismo y la creación de empleos formales e informales en Santa Cruz, condado situado en el estado de Rio Grande do Norte. La metodología utilizada fue principalmente cualitativa, que se han realizado, las primeras entrevistas con los dueños de las empresas del sector turístico, Y después de aplicar un cuestionario con la gente de trabajo en la principal atracción turística. Los principales resultados mostraron que la creación de empleo en la ciudad está directamente relacionada con el perfil de necesidad del visitante del turismo religioso, en este caso el sector de la restauración. Sin embargo, el sector hotelero no fue significativamente incrementado por la inserción de la actividad de turismo religioso.

Palabras clave: Turismo. Destino religioso. Trabajo. Informalidad.

\section{INTRODUÇÃOO}

A expressividade do turismo em âmbito mundial como atividade geradora de renda, negócios e incentivadora do desenvolvimento econômico concede ao setor visibilidade notável e, consequentemente, insere a atividade turística no discurso político, onde atribui-se a ele a função de dinamização das atividades tradicionais e exploração de novas possibilidades econômicas, enfatizando a distribuição de renda e emprego para as comunidades receptoras da atividade. Nessa perspectiva, o governo de muitos países vem propondo políticas públicas de organização e desenvolvimento do turismo no desígnio de promover a ascensão e equidade social.

No Brasil, desde a década de 1990, vem se discutindo modelos de políticas públicas, que interfiram diretamente e configurem um escopo necessário para a formação de estruturas econômicas e de atrativos turísticos, no intuito de alcançar a distribuição de renda e geração de emprego para todo o país. Baseando tais ações na criação de atrativos turísticos com essência brasileira por meio de uma gestão descentralizada, bem como por colaboração regional entre atores da atividade turística (CORIOLANO, 2005; BRASIL, 2007 e 2013). Para tanto, foi atribuída uma responsabilidade maior aos estados e municípios na criação de condições necessárias para o desencadeamento do turismo em seus territórios. 
Sendo assim, as questões centrais dessa pesquisa são: Como o turismo está contribuindo de fato para a geração de trabalhos formais e informais no município de Santa Cruz/RN? Qual a categoria que prepondera, a informal ou formal?

O objetivo central dessa pesquisa é compreender como a atividade turística influência no mercado de trabalho formal e informal em Santa Cruz-RN. A pesquisa busca realizar também o levantamento do quantitativo de ocupação no principal atrativo do município, o "Complexo Turístico Religioso Alto de Santa Rita de Cássia"; entender a dinâmica do mercado de trabalho no referido destino, especialmente, no tocante a atividade turística, subjacente a isso fazer o levantamento de empregos formais e informais nos empreendimentos turísticos da localidade.

\section{DESCRIÇÃO DO CASO DE ESTUDO - SANTA CRUZ/RN}

O município de Santa Cruz está localizado a $115 \mathrm{Km}$ da capital do estado do Rio Grande do Norte, com uma população de 39.300 habitantes, (IBGE3 Cidades, 2017) e tem sua economia baseia-se no comércio varejista, cerâmicas, panificação, indústria têxtil e avicultura, além de ser o maior exportador de frango do estado. Desde 20094 faz parte da Região Turística do Polo Agreste/Trairi e destaca-se como a cidade polo e referencial para o turismo, diante dos municípios que encontram-se inseridos no recorte da referida região.

A justificativa para escolher Santa Cruz como recorte espacial de investigação se fundamenta tendo em vista a relação exercida entre as ações do poder público para o desenvolvimento do turismo e a criação de empregos. O município torna-se um cenário importante no desenvolvimento dessa pesquisa, por ser um dos poucos municípios no Estado do Rio Grande do Norte, longe de atrativos naturais e do tão almejado binômio - sol e mar5, que se inseriu no mercado de produtos turísticos religiosos do nordeste, onde o incentivo ao turismo partiu em primeira ordem, do poder público, em associação com a igreja católica.

Nos últimos anos identificou-se uma série de ações do poder público municipal e federal na tentativa de desenvolver o turismo no município, sendo a primeira materialização desse intuito, a construção do Alto de Santa Rita de Cassia6 (Figura 1). Tal ação possibilitou o reconhecimento do município como destino religioso, fazendo-o atualmente receber um fluxo considerável de visitantes. No ano de 2014, o atrativo turístico recebeu cerca de 70 mil turistas 7.

Não obstante, é necessário mencionar que o projeto de turismo religioso no município tem uma base nas tradições religiosas e espontâneas da região, no qual os festejos e as cerimonias religiosas dedicadas a Santa Rita de Cassia têm expressividade de participação da população

\footnotetext{
${ }^{3}$ Instituto Brasileiro de Geografia e Estatística.

${ }^{4}$ Decreto n ${ }^{\circ} 21.390$, de 11 de novembro de 2009, lêr Silva, (2014), para maiores informações.

${ }^{5}$ Segmento este consolidado no território potiguar,

${ }^{6}$ Obra realizada com recursos federais, oriundo de emendas parlamentares, no total o repasse foi de 2.242.500,00. Período do convenio foi 31/12/2007 a 30/01/2011. Dados do Projeto de Pesquisa Política e turismo no interior potiguar: avaliação dos investimentos públicos. Coordenado por Rodrigo Cardoso da Silva e Clébia Bezerra da Silva.

${ }^{7}$ Dados da Secretaria de Turismo do município de Santa Cruz -RN.
} 
SILVA, Aline Mayara Marinho Xavier; SILVA, Rodrigo Cardoso da. Turismo e Trabalho: Uma Análise do Destino Religioso Santa Cruz RN. Revista Hospitalidade. São Paulo, volume 14, n.02, p. 01-23,

local e dos municípios vizinhos. Essa tradição de festejos religiosos têm ganhado força nos últimos 60 anos, quando se passou a realizar sistematicamente os festejos e as programações religiosas.

O ano de 2008 é emblemático para a Santa Cruz e para a gestão do Prefeito Luiz Antônio de Farias (2001 a 2008), onde o projeto de turismo religioso teve início e contou com o apoio das autoridades locais.

Figura 1: Alto de Santa Rita de Cássia

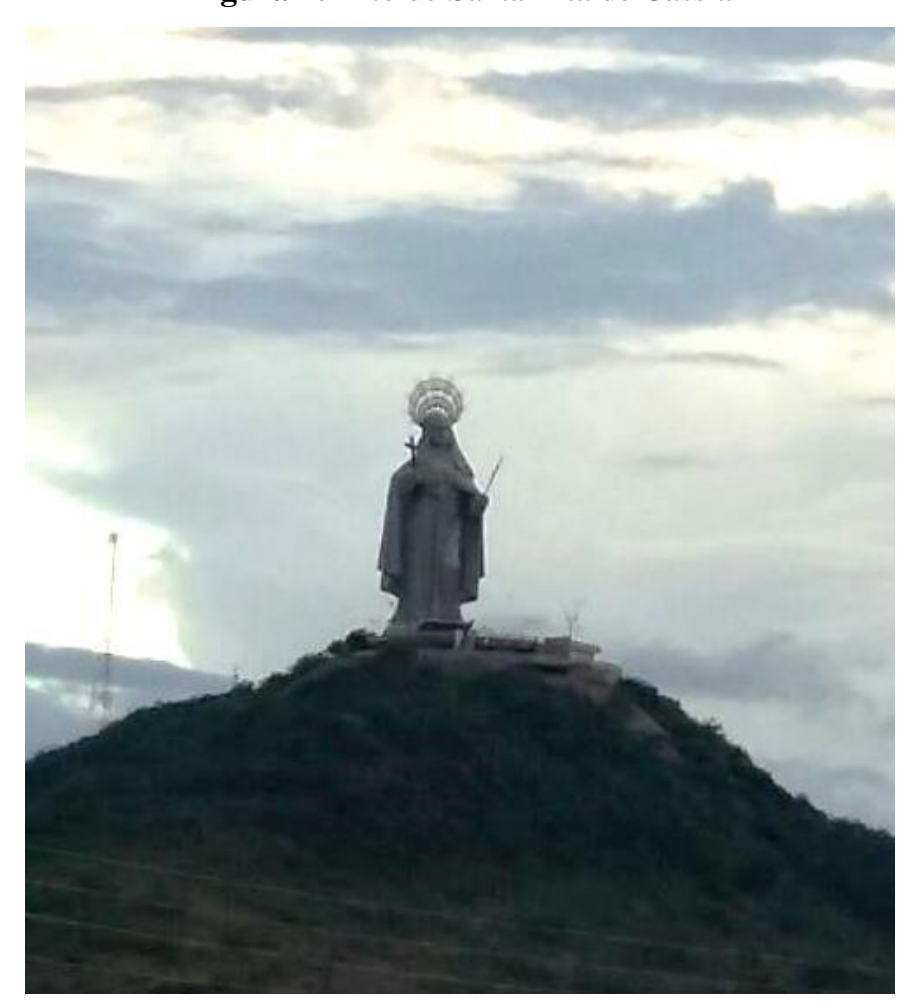

Fonte: Secretário de Turismo de Santa Cruz - RN (2015).

O turismo religioso em Santa Cruz foi incentivado pelo poder público com o objetivo de impulsionar a economia do município. E para ampliar ainda mais as possibilidades de geração de emprego nesse sentido, o poder público passou a investir em melhorias na infraestrutura local e a criar outros atrativos, através de recursos oriundos do Ministério do Turismo. A última ação pública para o incremento da atividade é a implementação de um teleférico (obra em andamento), cuja intenção foi ampliar a estrutura turística do município e alavancar ainda mais a demanda de visitantes/turistas para o destino.

O turismo pode favorecer diversos setores na medida em que oferece novas oportunidades de trabalho para as pessoas que se encontram na região turística, fato que justifica a pertinência de um estudo realizado no recorte proposto, o qual prime por identificar como o turismo pode influenciar no desenvolvimento de empregos, sendo eles formais ou informais.

Nesta perspectiva, pode-se afirmar que o predomínio do segmento religioso se estabeleceu no município de Santa Cruz e alavancou uma demanda específica de visitação, 
diferente da consolidada no RN. Sendo assim, a parceria entre igreja católica e gestão municipal foi primordial para colocar o projeto em movimento, construindo assim, a maior estrutura religiosa católica do Brasil. Nesse sentido, ao longo dos anos e pela conjuntura temática do município, é necessário estudar como o mercado de trabalho vem se comportando nesse destino religioso.

Há uma potencialidade nessa temática de estudo, especialmente, considerando que o turismo e a relação com o desenvolvimento de postos de trabalho, em grande medida, vêm oportunizar e despertar para um debate sobre a eficiência do turismo no seu papel de criador e dinamizador da economia local. Destaca-se, ainda, que existe uma lacuna de estudos nesse sentido, o que amplia a necessidade investigativa de profissionais da área por essa temática.

Para o dimensionamento conceitual que irá ser tratado nos resultados nesse trabalho, é necessário iniciar um debate e esclarecimentos iniciais sobre trabalho formal e informal, bem como sua relação com o turismo.

\section{TRABALHO FORMAL E INFORMAL}

Muitos são os fatores que influenciam o mercado de trabalho, tais como: flutuações econômicas, crises internacionais, ondulações no mercado global, falência de modos de produção, revolução tecnológica, dentro outros. Sendo assim, os trabalhadores que se encontram em classes sociais mais precárias buscam desenvolver seus meios de sobrevivência, muitas vezes surgem a partir de ocupações alternativas, empresas não legalizadas e comércios irregulares, formas diversificadas de sustento. O resultado dessa dinâmica é trabalhadores sem registros, e sem direitos básicos como carteira assinada e todas as outras seguridades sociais.

Para Soares (2005), o setor informal é um conjunto de empresas domésticas e de trabalhadores autônomos, que mesmo sem intenção deliberada, não pagam impostos e contribuições previdenciárias, ou seja, desta forma se posicionam a margem da legislação trabalhista e os sistemas de proteção social. Entretanto, essa situação acontece à revelia do sujeito em grande medida pela ignorância dos seus direitos ou mesmo por normalizar condições subhumanas de trabalho. Além disso, há aqueles que naturalizam esse tipo de ocupação como normal e se alienam enquanto trabalhadores, pois não percebem a própria dinâmica da vida que ocupam na sociedade.

Percebe-se que a atividade informal é identificada como um problema para a economia e a sociedade, uma vez que a classe trabalhadora quando está em situação de informalidade ela não está inserida no mercado de forma legal. Segundo Krein e Weishaupt (2010, p. 9) "Os termos "formal" e "informal" aparecem em substituição à dicotomia entre setor tradicional e setor moderno, uma vez que o setor informal é entendido como fenômeno moderno e resultado do processo de urbanização".

De acordo com os autores, a formalidade e informalidade do trabalhado se encontram em divergência porque o primeiro é caracterizado por ser tradicional e está dentro dos parâmetros 
legais que a sociedade impõe e o segundo emerge junto com a urbanização, sendo considerado um fenômeno moderno, pois não segue os conceitos legais impostos pela sociedade.

A teoria dos circuitos da economia urbana criada por Milton Santos divide a economia em circuito inferior e circuito superior. E cada circuito ocupa um lugar de destaque em meio ao cenário social e de proteção diferenciada para os trabalhadores inseridos em cada um desses circuitos. Montenegro (2006, p. 15) faz uma ressalva sobre o conceito da informalidade enfatizado no circuito inferior, mostrando que tal circuito é composto por um grande número de pessoas que trabalham com condições precárias e caracterizado por trabalho mal remunerado e com uma jornada de trabalho muito longa, sendo uma atividade temporária sem regulamentação.

Diante do que foi apresentado nota-se a precariedade do setor informal promove a desvalorização o trabalho e consequentemente traz pouco benefício para classe trabalhadora, principalmente no que tange aos direitos e dignidade de sobrevivência.

Montenegro (2006) menciona que o circuito superior é composto por bancos, atacadistas, transportadoras, indústria moderna, indústria de serviços. O circuito superior é a parte no mercado de trabalho mais favorecida onde se encontra empresas regulamentadas de acordo com a legislação trabalhista, e o trabalhador tem direito a todos os benefícios sociais que o governo oferece. Entretanto, na economia urbana pode-se perceber várias formas de trabalho que derivam da modernização do mercado, as classes trabalhadoras se encontram divididas devido a condição social da população.

O Serviço Brasileiro de Apoio à Micro e Pequena Empresa (SEBRAE) é um órgão que contribui com a formalização dos trabalhadores no mercado. Desde 2006, a instituição vem colocando em prática uma legislação alternativa pensada para os trabalhadores informais, dando acesso a alguns direitos que a legislação trabalhista atual permite.

Na aplicação da Lei Geral das micro e pequenas empresas criada em 14 de dezembro de 2006, o (SEBRAE, 2012) menciona que:

[...] a aplicação de políticas públicas desenvolvida no âmbito dos municípios e que visam estimular o desenvolvimento econômico local através da realização de ações concretas de incentivo e estimulo as micro e pequenas empresas, em especial depois da aprovação da lei complementar n ${ }^{\circ} 123$, conhecida como Lei Geral das Micro e Pequenas Empresas, e da sua regulamentação através de leis municipais.

O SEBRAE possibilitou, com o a criação dessa lei, uma maneira de incentivar o desenvolvimento econômico indireto de alguns trabalhadores, pois permite aos autônomos a legalização dos suas formas de trabalho, por meio da legalização enquadrando os trabalhadores informais como microempreendedores individuais.

A lei dos MEIs aborda como deve ser o planejamento e a inserção dos trabalhadores que ainda não se encontram de acordo com a legislação trabalhista, proporcionando direitos que podem ser equiparados ao trabalhar formal.

O microempreendedor individual é uma oportunidade para os trabalhadores, pois possibilita a formalização de atividades autônomas pode possibilitar melhor qualidade de vida 
para as pessoas envolvidas, além de ter direito a todos os benefícios sociais que o governo oferece a todos os trabalhadores legalizados.

Diante das discussões entre formalidade e informalidade entende-se que atualmente existem inúmeras possibilidades que auxiliam na regulamentação do mercado de trabalho. Veja a seguir o quadro 1, com algumas ocupações e profissionais que podem ser beneficiados por essa lei. Em destaque foi feito uma seleção para o setor de turismo.

Quadro 1 - Profissões que estão de acordo com a Cartilha do MEI

\begin{tabular}{|c|c|}
\hline \multicolumn{2}{|c|}{ PROFISSÕES } \\
\hline Agente de viagens & Proprietário de hospedaria \\
\hline Guia de turismo & Proprietário de restaurante \\
\hline $\begin{array}{c}\text { Organizador de excursões em } \\
\text { veículo próprio, municipal. }\end{array}$ & $\begin{array}{c}\text { Transportador aquaviário para passeios } \\
\text { turísticos }\end{array}$ \\
\hline $\begin{array}{c}\text { Proprietário de albergue não } \\
\text { assistencial }\end{array}$ & $\begin{array}{c}\text { Humorista e contador de histórias } \\
\text { Instrutor de idiomas }\end{array}$ \\
\hline Animador de festas & Fotógrafo aéreo / submarino \\
\hline
\end{tabular}

Fonte: Micro Empreendedor Individual (2014)

Percebe-se que algumas profissões que estão inclusas no MEI, e entre essas diversas profissões estão algumas relacionadas ao turismo, ou seja, a atividade turística é uma forte influenciadora para o desenvolvimento de trabalhos informais no mercado. Nesta vertente, entende-se que o turismo gera benefícios como emprego e renda, mas também pode ocasionar o desenvolvimento de trabalhos informais nos destinos turísticos, pois a própria iniciativa legislativa mostra essa natureza da atividade turística, para, além disso, há uma literatura extensa sobre planejamento de destinos turísticos que fundamenta essa percepção, porém a ratificação dos órgãos regulamentadores é ainda mais respaldada socialmente.

O mercado de trabalho possui inúmeras possibilidades para a criação de empregos, o turismo é uma atividade que se apropria dos espaços e causa transformações rápidas, por isso, é caracterizado por proporcionar novas oportunidades de trabalho. A atividade turística motiva a geração de empregos e, simultaneamente, com a geração desses empregos surgem os trabalhos informais devido à prática do turismo. Para Anjos (2011, p. 21).

O turismo e a oferta que dependem essencialmente da mão-de-obra e do consumo turístico motivam a geração de empregos o que efetiva sua validade social e econômica. Por outro lado, o turismo por meio do emprego informal, exclui os benefícios sociais do conjunto da população e impossibilita o desenvolvimento socioeconômico dos autóctones que na economia informal e intermitente, poucos colhem dos benefícios da atividade. 
O autor faz uma ressalva dizendo que o turismo é uma atividade que motiva a geração de emprego, desta forma impulsiona a economia, entretanto, para além dos pontos positivos, o turismo também proporciona um grande fluxo de trabalhos informais que excluem os benefícios sociais da população e os trabalhadores realizam seus trabalhos em condições precárias. Tendo em vista que os trabalhadores precisam atender de forma rápida e para não perder o momento enfrentando ocupações com pouca seguridade, mas se aventuram mesmo sabendo que há muito tralhado e pouco retorno na maioria das vezes. Em contrapartida, a atividade turística se estabelece no mercado como uma possibilidade de crescimento econômico, mesmo causando impactos negativos e que não favorecem a economia. Para o desenvolvimento do turismo é preciso ter um planejamento adequado que se preocupe com as ações que pode impactar o espaço. Por isso, Soares (2005, p. 95) relata alguns objetivos que diminuiria a informalidade no turismo.

[...] 1 - apoiar a criação de empresas turísticas locais com a capacitação e a profissionalização da comunidade; 2 - redistribuir os fluxos de turistas; 3- criar condições para trocas equitativas, conciliando os interesses de seus agentes; 4 - evitar a "monocultura turística", e 5- orientar o investimento de capitais externos.

Nesse sentido, Soares discute que é preciso incluir mais políticas públicas no planejamento da atividade turística, inserir a população no processo de concepção da atividade, pois o desenvolvimento local do destino depende das da integração sociedade, mercado e poder público. A implantação de empresas turísticas pode gerar um fluxo de trabalhos formais e capacitar profissionalmente a população para trabalhar com a atividade, ocasionando um número menor de trabalhadores informais. Além disso, orientar os investimentos externos é a principal forma de evitar exploração desenfreada dos espaços e recursos turísticos e esta é uma prerrogativa do poder público.

\section{METODOLOGIA DO ESTUDO}

Para fins da pesquisa utilizou-se uma abordagem qualitativa, a qual não requer uso de métodos de estatística, e nesse caso, "o ambiente natural é a fonte direta para coleta de dados e o pesquisador é o instrumento chave da pesquisa" (SOUSA \& OTANI, 2007, p. 40). Nesse sentido, foram feitas entrevistas nos empreendimentos ligados ao setor turístico do município estudado. O roteiro da entrevista semiestruturada foi elaborado, especialmente, com questões referentes a força de trabalho necessária, as mudanças com a chegada do turismo, e acerca das perspectivas dos empreendedores quanto ao turismo em Santa Cruz-RN. Fechando assim uma dimensão importante da pesquisa, que é entender as mudanças acarretadas pelo o turismo no mercado diretamente afetado pela atividade.

Para o tratamento dos dados utilizou-se da técnica análise de conteúdo de Bardin (2005), seguido de uma análise temática sobre as falas dos sujeitos entrevistados. A pesquisa foi realizada de julho a novembro de 2015.

A seguir, o Quadro 2 apresenta as empresas que foram entrevistadas nesse trabalho, a seleção delas foi realizada com base nos dados do Inventário da Oferta Turística de Santa Cruz 
(2013), que informa aqueles estabelecimentos que atuam diretamente na atividade turística. Foi identificado um quantitativo de 15 estabelecimentos.

Quadro 2 - Equipamentos que foram entrevistados e que foram levantados pelo inventário turístico do município de Santa Cruz.

\begin{tabular}{|c|c|}
\hline MEIOS DE HOSPEDAGENS & ALIMENTOS E BEBIDAS \\
\hline Pousada e Restaurante Panela Quente & Panificadora Bela Manhã \\
\hline Pousada Brasa & Padaria Seridó \\
\hline Pousada Santa Rita I & Day Night Bar \\
\hline Pousada Santa Rita II & Restaurante Sabor Sertanejo \\
\hline Hotel Pousada Nova Aliança & Panificadora Elite \\
\hline Pousada Riviera & Hotel e Restaurante Refúgio e Requinte \\
\hline Pousada Dallas & Restaurante e Pizzaria Bom Demais \\
\hline
\end{tabular}

Fonte: Inventário turístico de Santa Cruz (2013).

Foram aplicados na segunda fase da pesquisa 50 questionários com os trabalhadores que estão exercendo alguma atividade no "Alto de Santa Rita de Cássia", tal instrumento de pesquisa teve como base para o desenvolvimento do questionário o instrumento de Costa (2007), que buscou investigar como trabalhadores informais do litoral potiguar desenvolviam suas atividades no mercado turístico do litoral. Essa ação de pesquisa contempla outra dimensão da pesquisa que é entender o trabalho informal no principal atrativo do município.

A técnica de observação e de diário de campo foi utilizada com o intuito de levantar a percepção da realidade e obter dados, bem como lembrar e registrar impressões nas coletas e aplicação dos instrumentos de pesquisa.

Os resultados serão apresentados em duas vertentes de análise: a primeira, destacando os empreendimentos formais, as mudanças com a implementação do turismo, bem como a informalidade do trabalho; e a segunda, focada no principal atrativo do município na tentativa de conhecer melhor os empregos gerados, e tentar traçar um panorama do ambiente dos trabalhadores, questionando, principalmente, qual a renda e as condições de trabalho.

\section{MERCADO DE TRABALHO FORMAL E INFORMAL NOS EMPREENDIMENTOS DE TURISMO EM SANTA CRUZ}

Na primeira parte dos resultados da presente pesquisa destinou-se a fazer o levantamento dos trabalhos formais nos equipamentos de hotelaria e de alimentos e bebidas em Santa Cruz. Para o alcançar dos resultados, selecionou-se 15 (quinze) empreendimentos locais com base no Inventário Turístico do município, e desses estabelecimentos, 7 (sete) eram empresas do setor de 
hospedagem. Elucida-se que as entrevistas com os proprietários foram realizadas de 10 a 24 de outubro de 2015, em alguns casos, os funcionários é que responderam a entrevista.

Nesse processo de pesquisa levou-se em consideração também algumas observações relevantes das entrevistas e das visitas feitas aos empreendimentos, observações que foram compiladas e serão apresentadas a seguir. Trata-se de expor, primeiramente, a visão dos empresários sobre o mercado de trabalho no tocante a atuação de suas empresas e a concepção desses quanto ao turismo no município.

Assim, quando questionados sobre mudanças na oferta de empregos em suas empresas, e se houve a necessidade de contratação extra após a construção do principal atrativo do município (figura 1), pode-se verificar praticamente uma unanimidade dos empresários ao relatarem que não houve necessidade de expandir o quadro de funcionários após os investimentos feitos pelo poder público no turismo, pois o perfil de seus clientes em sua maioria são representantes comerciais e profissionais que estão apenas a trabalho no município, mencionaram também que esse perfil têm sido pouco inalterado. Consequentemente, tem-se que o movimento no setor de hospedagem acontece durante a semana, iniciando na segunda-feira e se arrefecendo da quinta para a sexta-feira.

Vale ressaltar que apenas um dos sete empreendimentos de hospedagem teve aumento de funcionários, sendo este o Hotel Nova Aliança, que possui hoje uma sede e uma filial no município, os funcionários aumentaram, mas em contrapartida atende um público restrito que se volta para representantes comerciais e pessoas a trabalho, onde o turismo não foi mencionado como aspecto relevante para esse aumento.

Outro argumento destacado pelos empresários é que a demanda para o segmento do turismo religioso no município é incipiente e os poucos turistas que pernoitam vêm ao município apenas nos fins de semana, justamente, quando os estabelecimentos estão praticamente vazios. Sendo assim, na prática de gestão dos empreendimentos não se necessitou ampliar o quadro de funcionário, pois a oferta de unidades habitacionais estava ociosa e foi totalmente absorvida.

A única exceção para contratar funcionários em funções temporárias é no início de maio, quando o município está recebendo um maior fluxo de pessoas, em virtude da festa da padroeira e as festividades do mês, gerando então uma demanda rápida de serviço.

Com as entrevistas e visitas foi possível identificar a quantidade de trabalhadores formais nos empreendimentos de hospedagem, logo, a Tabela 1, a seguir, mostra a quantidade de funcionários que exercem o trabalho formal ${ }^{8}$ e informal ${ }^{9}$ em cada empreendimento.

\footnotetext{
${ }^{8}$ Considera-se nesse artigo o trabalhador formal - aquele que está de acordo com a legislação trabalhista no Brasil, exemplo CLT (Consolidação das Leis trabalhistas de 1943).

${ }^{9}$ Trabalhador que desenvolve atividades sem vínculos com empreendimentos ou instituições, em condição de tempo esporádica, sem formalização de nenhum direito trabalhista e sem seguridade social
} 
Tabela 1- Quantidade de funcionários nos meios de hospedagens: formais e informais.

\begin{tabular}{c|c|c}
\hline \hline $\begin{array}{c}\text { EQUIPAMENTOS DE } \\
\text { HOSPEDAGEM }\end{array}$ & $\begin{array}{c}\text { TRABALHADORES } \\
\text { FORMAL }\end{array}$ & $\begin{array}{c}\text { TRABALHADORES } \\
\text { INFORMAL }^{10}\end{array}$ \\
\hline Empreendimento 1 & --- & 2 \\
\hline Empreendimento 2 & 1 & 1 \\
\hline Empreendimento 3 & 3 & --- \\
\hline Empreendimento 4 & 3 & --- \\
\hline Empreendimento 5 & 11 & 4 \\
\hline Empreendimento 6 & 2 & --- \\
\hline Empreendimento 7 & 2 & 9 \\
\hline Total & 22 & \multicolumn{2}{|c}{} \\
\hline \hline
\end{tabular}

Fonte: Dados da pesquisa (2015).

Percebe-se que quatro empresas possuem trabalhadores informais, empreendimento 1,2, 3 e 6. Constatou-se que os estabelecimentos em questão têm uma gestão familiar e grande parte dos funcionários também possuem vínculo familiar com o proprietário. Com a realização dessa pesquisa notou-se que o turismo não influenciou de forma relevante a abertura de novas oportunidades de trabalho no que se refere ao setor de hospedagem, já que de acordo com os gestores dos empreendimentos as suas demandas são praticamente de representantes comerciais e pessoas com ocupação profissional no município. Outro fato interessante a ser destacado é que $29 \%$ das vagas de trabalho nos meios de hospedagem são informais, sendo considerado um percentual elevado.

Tabela 2 - Quantidade de funcionários antes e depois da construção do complexo Alto de Santa Rita de Cassia

\begin{tabular}{c|c|c}
\hline \hline $\begin{array}{c}\text { EQUIPAMENTOS DE } \\
\text { HOSPEDAGEM }\end{array}$ & $\begin{array}{c}\text { QUANTIDADE DE } \\
\text { FUNCIONÁRIOS ANTES DO } \\
\text { ALTO DE SANTA RITA } \\
\left(2010^{*}\right)\end{array}$ & $\begin{array}{c}\text { QUANTIDADE DE } \\
\text { FUNCIONÁRIOS DEPOIS DO } \\
\text { ALTO DE SANTA RITA } \\
(2015)\end{array}$ \\
\hline Empreendimento 1 & 2 & 2 \\
\hline Empreendimento 2 & 3 & 3 \\
\hline Empreendimento 3 & 4 & 3 \\
\hline Empreendimento 4 & 3 & $\mathbf{1 1}$ \\
\hline Empreendimento 5 & $\mathbf{4}$ & 2 \\
\hline Empreendimento 6 & 6 & 31 \\
\hline Empreendimento 7 & 2 & \\
\hline Total & 24 & \\
\hline \hline & Ano de inauguração do Alto de Santa Rita de Cassia \\
& Fonte: Dados da pesquisa (2015).
\end{tabular}

De acordo com tabela 2 acima, nota-se que apenas o Empreendimento 5 aumentou a quantidade de trabalhadores, ou seja, antes do complexo turístico contava-se apenas com 4 funcionários, e nos dias atuais o estabelecimento dispõe de 11 colaboradores. Conclui-se que

\footnotetext{
${ }^{10}$ Informais no sentido de não prestarem serviços contínuos, havendo atividades esporádicas.
} 
apenas um empreendimento teve mudanças em seu quadro de funcionários, o que gerou um crescimento do setor de $29 \%$ no acumulado de 5 anos.

Explica-se que esse crescimento deu-se de forma secundária ao turismo, não foi ocasionado diretamente pela demanda de hospedagem dos turistas, e sim por necessidade de especialização do serviço em função da clientela. Atualmente, o empreendimento 5 que dispõe de uma melhor infraestrutura, e tem localização privilegiada (próximo ao centro comercial) no município. Dessa forma, com base nos dados da tabela 2 constatou-se que o turismo religioso no município não favoreceu e/ou aqueceu os empreendimentos hoteleiros, uma vez que apenas uma empresa aumentou o número de trabalhadores, enquanto as demais permaneceram estagnadas.

Os empresários relataram que o turismo não contribuiu de forma efetiva para os empreendimentos em termos econômicos devido a permanência do turista não ser prolongada no município e o fluxo de visitantes ser apenas nos finais de semana, tendo esse fato implicado também na estagnação no quadro de funcionários nas empresas. Assim, a seguir, elencou-se alguns relatos dos empresários entrevistados sobre o turismo e as principais dificuldades para o setor de hospedagem, enfatizando suas vivências com os turistas.

\footnotetext{
"O fato de não ter hospedagem todos os finais de semana agregando isso ao Alto, é porque Santa Cruz ainda não tem roteirização turística, não tem outro atrativo, além do Alto. Isso faz com que o turista faça a visita em apenas um dia." (Entrevistado 1)

"Não existe uma sinalização que ajude aos turistas a chegar ao complexo turístico, e muitos perguntam, além do Alto e do museu, existe algo mais." (Entrevistado 2)

"O pessoal reclama muito por falta de opção, por não ter nada além do santuário." (Entrevistado 3)
}

"Eu não conheço turismo aqui em Santa Cruz, não tem opções para os turistas ficarem na cidade". (Entrevistado 4)

Nesse escopo, observa-se que o segmento do turismo religioso não impacta diretamente os empreendimentos da hotelaria no município, pois o deslocamento em função do turismo religioso é breve e rápido, pois logo após a visita ao local de devoção muitos dos entrevistados deixam o município. Em contrapartida, há uma possibilidade de aumentar essa experiência turística religiosa, com investimentos em atrativos complementares que atraiam o interesse da demanda de visitante já existente.

Dessa maneira, o poder público precisa de fato se atentar para criar as oportunidades de incremento ao turismo, sendo o planejamento municipal uma das vertentes para se alcançar esse patamar, de modo que, estabeleça um trabalho em sintonia com os atores locais da atividade. 


\section{EQUIPAMENTOS DE ALIMENTOS E BEBIDAS}

Nessa seção, examinou-se as mudanças no mercado de trabalho dos equipamentos de alimentos e bebidas (A\&B) do município, tendo a análise se pautado no resultado da investigação feita em 8 empresas identificadas no inventário da oferta turística do município (ver quadro 2).

De forma resumida, têm-se que 6 empreendimentos ${ }^{11}$ apresentam um panorama semelhante, em que seu quadro de funcionários não aumentou com as intervenções do poder público no turismo do município de acordo com as entrevistas, bem como as próprias informações repassadas pelos os empresários. A clientela que tais empresas atendem em sua maioria são os representantes comerciais ou pessoas a trabalho, seguida da população local, com a diferença de nos finais de semana ter um fluxo incrementado em virtude do turismo religioso.

Os gestores desses empreendimentos relatam que a contratação temporária é uma prática comum no período de alta estação, que seria durante as festividades religiosas do município (mês de maio).

Em contrapartida, dois ${ }^{12}$ casos de aumento de vagas de empregos foram identificados. No primeiro empreendimento o aumento chegou a duplicar a quantidade de vagas de empregos. Nesse estabelecimento, antes da inserção do turismo, contava-se apenas com 40 funcionários, e nos dias atuais há cerca de 87 funcionários, essa realidade veio a se concretizar pela demanda nos finais de semana e de uma especialização maior na oferta do serviço. No segundo empreendimento mencionado aumento o quadro de funcionários em cerca de 10 vagas, ou seja, onde existiam 30 colaboradores, após a inserção do turismo, veio a necessitar de mais 10 funcionários. $\mathrm{O}$ perfil da clientela refere-se em sua maioria aos visitantes/turistas dos finais de semana, seguido de pessoas a trabalho e da população local que aquecem o setor durante a semana.

Ressalta-se que esses dois empreendimentos identificados por essa pesquisa, são também os dois maiores empreendimentos do ramo de A\&B do município, que dispõem de serviços mais especializados e que podem receber um grande fluxo de pessoas ao mesmo tempo em virtude da infraestrutura dos estabelecimentos. Tal fato se alinha ao perfil do visitante do principal atrativo do município, a saber, os romeiros e as caravanas. A seguir, tem-se a Tabela 3 com os dados coletados na pesquisa.

\footnotetext{
${ }^{11}$ Panificadora Bela Manhã; Day Night Bar; Churrascaria Boi Gordo; Restaurante Sabor Sertanejo; Hotel e Restaurante Refúgio e Requinte; Restaurante e Pizzaria Bom Demais.

${ }^{12}$ Ver Tabela 3 os dois casos registrado foram nos empreendimento A\&B2 e A\&B6
} 
Tabela 3 - Quantidade de trabalhadores: variação após a inserção do turismo

\begin{tabular}{c|c|c}
\hline \hline EQUIPAMENTOS DE A\&B & $\begin{array}{c}\text { QUANTIDADE DE } \\
\text { FUNCIONÁRIOS ANTES DO } \\
\text { ALTO DE SANTA RITA } \\
(2010)\end{array}$ & $\begin{array}{c}\text { QUANTIDADE DE } \\
\text { FUNCIONÁRIOS DEPOIS DO } \\
\text { ALTO DE SANTA RITA } \\
(2015)\end{array}$ \\
\hline A\&B 1 & 3 & 3 \\
\hline A\&B 2 & $\mathbf{4 0}$ & $\mathbf{8 7}$ \\
\hline A\&B 3 & 9 & 6 \\
\hline A\&B 4 & 6 & 3 \\
\hline A\&B 5 & 3 & $\mathbf{4 0}$ \\
\hline A\&B 6 & $\mathbf{3 0}$ & 8 \\
\hline A\&B 7 & 8 & 8 \\
\hline A\&B 8 & 8 & 164 \\
\hline Total & 107 & \multicolumn{2}{c}{} \\
\hline \hline
\end{tabular}

Fonte: dados da pesquisa (2015).

O crescimento de empregos no setor de alimentos e bebidas foi de 53\%, em uma perspectiva de 5 anos, porém percebeu-se que os empreendimentos foram favorecidos de forma tímida com a atividade turística no município, pois ocasionou mudanças no mercado de trabalho e tais mudanças concentraram-se em apenas dois casos, ou seja, provocou uma centralização de resultados. Atualmente, a maioria dos empreendimentos está com a mesma quantidade de trabalhadores de antes da inserção do turismo no município de Santa Cruz.

Nesse escopo, só os estabelecimentos com certa qualidade, no que concerne a conforto, capacidade de atendimento elevada e serviços diferenciados, foram favorecidos e acabaram absorvendo soma relevante de capital injetado na economia local. Nesse sentido, percebe-se que há uma tendência de centralização, onde os demais atores do mercado foram marginalizados dos benefícios do turismo. Ao reparar que o universo total é de 8 estabelecimentos, 6 estão fora do circuito de inserção de capital proporcionado pelo o turismo religioso, tal fato fundamenta a afirmação de centralização, bem como esses dados mostram a discrepância entre o discurso sobre o turismo e materialização dele no mercado de trabalho.

Deve-se ressaltar que apesar da atividade não ter possibilitado muitos benefícios econômicos, grande parte das empresas mantem seus trabalhadores devidamente legalizados no mercado. Esse aspecto é positivo, na medida em que se proporcionou a abertura de vagas com condições básicas de qualidade regidas nas leis trabalhistas em rigor. A seguir, na Tabela 4, há uma tentativa de se observar a informalidade do setor. 
Tabela 1 - Quantidade de Trabalhadores: formais e informais

\begin{tabular}{c|c|c}
\hline \hline EQUIPAMENTOS DE A\&B & $\begin{array}{c}\text { TRABALHADORES } \\
\text { FORMAIS }\end{array}$ & $\begin{array}{c}\text { TRABALHADORES } \\
\text { INFORMAIS }\end{array}$ \\
\hline A\&B 1 & 3 & --- \\
\hline A\&B 2 & 87 & -- \\
\hline A\&B 3 & 9 & -- \\
\hline A\&B 4 & 6 & 3 \\
\hline A\&B 5 & ---- \\
\hline A\&B 6 & 40 & --- \\
\hline A\&B 7 & 8 & --- \\
\hline A\&B 8 & 8 & 3 \\
\hline Total & 161 & \\
\hline \hline
\end{tabular}

Fonte: Dados da pesquisa (2015).

Com a pesquisa foi possível perceber que a maioria dos equipamentos de A\&B, em Santa Cruz, trabalha com os funcionários devidamente legalizados conforme a legislação trabalhista, e apenas o A\&B 5 possui funcionários ainda informais. Atualmente totaliza-se 161 funcionários, somando todas as vagas de empregos no setor de A\&B legalizados.

Esse crescimento de empregos nos estabelecimentos do setor deve-se em grande medida pela absorção do fluxo de pessoas gerado pelo segmento do turismo religioso, que se caracteriza pelo deslocamento de pessoas que não pernoitam e fazem uma alimentação rápida, desejando assim um serviço mais ágil. Acredita-se que foram essas as especificidades que motivaram a ampliação dos serviços de alimentação no município.

Desta forma, nota-se também que depois da chegada do complexo turístico ocorreram mudanças no quadro de trabalhadores das empresas, mas não em todos os equipamentos, pois apenas dois empreendimentos, como já mencionado, anteriormente, passaram por uma mudança significativa (A\&B 2 e A\&B 6).

O município de Santa Cruz ainda não está devidamente preparado para acolher a demanda que recebe, e em especial no quesito permanência do turista, sendo este essencial para o desenvolvimento econômico do mercado. Desta forma, percebe-se que o turismo no município não é permanente e a maior parte do fluxo de visita ao município se dá por meio de excursão, ou seja, só permanece um dia no município e, portanto são considerados visitantes.

Tal cenário apenas beneficia, de forma imediata, o setor de $\mathrm{A} \& \mathrm{~B}$, como os dados coletados demostram. Dessa maneira, a seguir serão expostos os relatos de alguns empreendedores do setor de A\&B de Santa Cruz sobre as dificuldades para o setor em que atuam.

"Eu acredito que se fosse mais bem divulgado o turismo religioso na cidade atrairia mais turistas". (Entrevistado 5)

"Eu acho que assim, pra ser lançado um ponto turístico como foi em Santa Cruz, é preciso investir mais em cursos, para que tenha mão de obra qualificada". (Entrevistado 6) 
"A cidade de Santa cruz está precisando de mais investimento, a abertura do comércio durante o final de semana é muito importante, pois a cidade teria mais rendimento econômico". (Entrevistado 7)

"Não saber se comunicar com meus clientes estrangeiros". (Entrevistado 8)

Nos depoimentos dos empreendedores e gestores das empresas, nota-se que ainda é difícil encontrar pessoas com qualificações para o setor de $A \& B$, e esse problema perpassa não só a produção do serviço de alimentação como aponta o entrevistado 5 , mas também atinge a comunicação pessoal com o cliente, de acordo com o entrevistado 8.

Nesse sentido, os horários de funcionamento dos empreendimentos, a falta de funcionários qualificados e a informação são elementos essenciais na ampliação da demanda. Mesmo assim, tais elementos ainda são negligenciados, significa então, que o mercado de serviços de Santa Cruz não se atentou ou ainda não é significativo o suficiente para mudar algumas práticas, consequentemente, isso aflora no horário de funcionamento, como relatado pelo o entrevistado 7, onde poucos são os estabelecimentos abertos e que tenham capacidade de atender a demanda gerada pelo o turismo religioso.

Diante das respostas dos proprietários, nota-se que uma das principais dificuldades de ser empreendedor no município de Santa Cruz, nos dias atuais, é a falta de atividades que envolvam os visitantes no local por mais tempo. Para contribuir com o crescimento econômico e desenvolvimento local, é preciso estruturar o município com atrativos que despertem o interesse do visitante, fazendo com que o mesmo permaneça mais dias no destino turístico.

Diante dos dados apresentados, identificou-se que não há um expressivo número de oportunidades de trabalho no município gerado pelo turismo, uma vez que das 15 empresas entrevistadas apenas 3 disponibilizaram mais vagas para contratar empregados nos últimos 5 anos. Em comparação com os demais, esses são os empreendimentos mais estruturados e com maior capacidade de atendimento do município, ou seja, demonstra uma gestão mais eficiente. Os demais empreendimentos continuam com a mesma quantidade de funcionários no mercado, ou seja, não foram afetados pela atividade turística de forma acentuada.

Em síntese, tem-se que o poder público do município deve refletir sobre novas estratégias de planejamento que envolva o potencial turista, com o intuito de aumentar a estada no destino e a utilização dos serviços que são oferecidos. É necessária a ampliação da influência da atividade na economia local, através das empresas hoteleiras e de alimentação, já que atualmente a cadeia produtiva do turismo ainda não está ligada diretamente ao mercado local. Outro ponto interessante é que não há empresas de turismo para trabalhar com receptivo no município, por esse motivo não houve uma sondagem nas agências de turismo.

\section{O MERCADO DOS TRABALHADORES INFORMAIS DO ALTO DE SANTA RITA DE CÁSSIA}

Neste bloco será analisado o perfil dos trabalhadores informais do Alto de Santa Rita de Cássia, onde foi feita a aplicação de 50 questionários com os ambulantes na intenção de verificar 
SILVA, Aline Mayara Marinho Xavier; SILVA, Rodrigo Cardoso da. Turismo e Trabalho: Uma Análise do Destino Religioso Santa Cruz RN. Revista Hospitalidade. São Paulo, volume 14, n.02, p. 01-23,

como o trabalho informal está constituído no principal atrativo do município. A seguir, na Figura 2, tem-se uma imagem ilustrativa do local de trabalho dos ambulantes do complexo turístico, bem como pode-se visualizar o lócus da aplicação dos questionários.

Figura 2 - Mercado informal do Alto de Santa Rita de Cássia

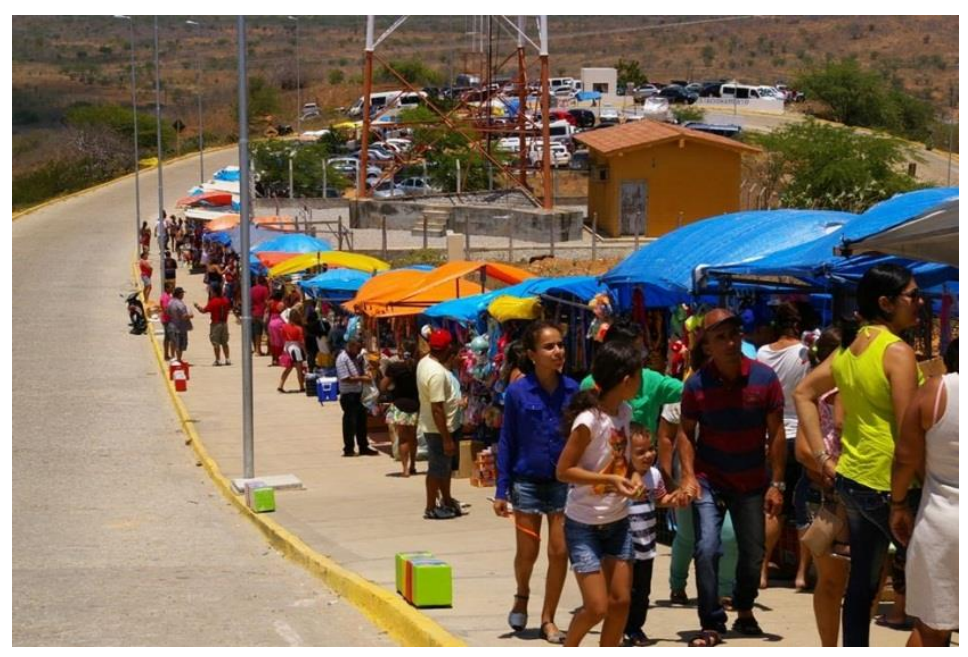

Fonte: Pesquisa de campo (2015).

Salienta-se que a amostragem não probabilística foi feita por conveniência, pois a população total de trabalhadores informais do atrativo é desconhecida, e nas visitas de campo em conversas com os próprios ambulantes e a líder da associação o número de pessoas vivendo desse trabalho é bem próximo do coletado, e a rotatividade desses trabalhadores é significativa.

Para iniciar a discussão sobre o aspecto da informalidade algumas informações básicas são essenciais, a seguir, a tabela 5 mostra o perfil dos trabalhadores do complexo turístico. Discernindo sobre o sexo, e se residem no município.

Tabela 5 - Perfil dos ambulantes, (gênero) e residentes.

\begin{tabular}{cccc}
\hline $\begin{array}{c}\text { Sexo } \\
\text { Masculino }\end{array}$ & $\begin{array}{c}\text { Sexo } \\
\text { Feminino }\end{array}$ & Residente do Município & $\begin{array}{c}\text { Total de Trabalhadores } \\
\text { Informais }\end{array}$ \\
\hline \hline 12 & 38 & 50 & 50 \\
\hline
\end{tabular}

Fonte: dados da pesquisa (2015)

O mercado de ambulantes (trabalhadores informais) do complexo é caracterizado com uma porção considerável de mulheres trabalhando. A existência do sexo feminino no mercado informal mostra que a mulher atualmente se posiciona, em muitos casos, como chefe da família necessitando assim contribuir com a renda familiar.

De acordo Delaney (2012, p.8), "nos países mais pobres, a maioria das mulheres abre empresas por necessidade econômica". Ainda segundo Delaney (2012, p8), “[...] em 2010, mais de 104 milhões de mulheres entre 18 e 64 anos estavam engajadas ativamente no lançamento e na condução de novos empreendimentos comerciais [...]". Nessa perspectiva, o mercado de informalidade de Santa Cruz vem acompanhando a tendência e a diferença aqui estão na informalidade do negócio e da ocupação. 
Percebeu-se através do levantamento que todos os trabalhadores empregados com uma ocupação no Alto de Santa Rita de Cássia são residentes do município. Em relação ao seu grau de escolaridade, foram apuradas as seguintes percentagens: duas delas despertam atenção, a primeira é que $42 \%$ dos trabalhadores pesquisados possuem ensino fundamental incompleto, e $10 \%$ apenas o ensino fundamental completo. Em seguinte com ensino médio completo apenas $24 \%$; com ensino médio incompleto $18 \%$ e apenas $6 \%$ com superior.

Logo, tais dados mostram que mais da metade desses trabalhadores possuem uma baixa escolaridade e para esses casos as oportunidades de emprego estão cada vez mais escassas, pressionados a enveredar em ocupações que oferecem pouca e/ou restrita qualidade de vida. As outras porcentagens constatadas também são relevantes, principalmente, os $6 \%$ com ensino superior, demonstrando que mesmo qualificados há uma dificuldade no estabelecimento de oportunidades, tornando-se continuada a cobrança de mais qualificação dos indivíduos.

Desta forma, constatou-se que a maioria dos trabalhadores informais do complexo turístico é uma população deficitária de educação. Tal resultado demonstra que as pessoas que trabalham no mercado informal se caracterizam por não ter a oportunidade de se inserir no mercado de trabalho formal, por falta de escolaridade e qualificação, apresentando-se como uma classe social menos favorecida, uma vez que realiza o trabalho informal como forma de sobrevivência.

Quando tratamos sobre a principal atividade econômica e geradora de renda dos trabalhadores, ou seja, quantos dos ambulantes vivem apenas da atividade econômica associada ao turismo, e quantos fazem isso de forma complementar?

Os dados mostram que $57 \%$ dos trabalhadores informais obtém uma renda mensal da atividade turística, mas desenvolvem outras atividades paralelas. Essa parcela dos ambulantes relata que o turismo é um complemento para renda familiar, pois ter somente um trabalho não é suficiente para suprir as necessidades básicas. Já $43 \%$ dos trabalhadores atuam no mercado informal e dedicam-se exclusivamente a atividade, ou seja, têm no turismo a forma única de obtenção de renda para fins da sobrevivência.

Sendo assim, pode-se dizer que o trabalho está relacionado aos conceitos de Woleck (2002) e principalmente da concepção de Marx, pois o trabalho é uma forma que o homem encontrou de utilizar os recursos da natureza, transformar os objetos para consumo próprio e como valor de troca para suprir suas necessidades básicas de sobrevivência.

Por outra vertente, o trabalhador mesmo empregado em outra função se submete a uma segunda ocupação sem nenhuma forma de seguridade social para poder suprir as necessidades individuais ou do seu grupo familiar. Dessa forma, o turismo religioso desenvolvido em Santa Cruz contribui com uma relação de subordinação do trabalhador ao trabalho. Construindo ambientes e ocupações potencialmente insalubre do ponto de vista financeiro e dilacerante com a perspectiva de qualidade de vida.

Nas visitas de campo, observou-se que o complexo turístico alto de Santa Rita de Cassia permitiu o incremento de ocupações no município, pois os trabalhadores que se beneficiam com a atividade informal relatam que a economia melhorou com a chegada do turismo, uma vez que 
surgiram novas oportunidades de trabalho. Alguns dos envolvidos com o mercado informal mencionaram que não tinham uma atividade remunerada que pudesse gerar seu sustento e revelaram que a atividade turística trouxe a possibilidade desses se inserirem no mercado de trabalho, mesmo que de forma "enviesada".

É fato que turismo estabeleceu oportunidades de trabalho para as classes menos favorecidas, ou ainda, com baixa escolaridade do município de Santa Cruz. Verificou-se uma porcentagem expressiva no tocante a quantidade de pessoas com baixa escolaridade que usufruem dessa ocupação informal como fonte principal de renda. Esse é aspecto do mercado informal que favorece à economia do município em detrimento dos envolvidos, os subordinando a condições pouco salutares profissionalmente.

Procurou-se saber também as motivações para o ingresso nessas ocupações informais, o resultado é que a principal motivação para a inserção no mercado informal foi a falta de empregos com $51 \%$ das afirmações, seguida de $40 \%$ que enxergou nesse tipo de atividade uma oportunidade para conseguir uma renda, de modo que essa margem corrobora com o resultado obtido anteriormente que refere-se aos trabalhadores que tem na atividade informal uma maneira de complementar a renda. Por fim, tem-se que uma quantidade reduzida de entrevistados revelou que já atuavam na atividade (vendas) de alguma forma, apenas $9 \%$.

Salienta-se que no instrumento de coleta de dados havia outras variáveis para justificar o interesse na atividade turística, tais como: conhecimento na área do turismo, indicação de terceiros e outros, mas essas não foram alternativas selecionadas pelos entrevistados. É notável que, em sua maioria, os trabalhadores entrevistados sentem-se beneficiados com atividade turística, pois o trabalho que eles desenvolvem atualmente depende do fluxo de visitação, gerando o apoio desses munícipes ao poder público local.

Dos 50 entrevistados que responderam ao questionário, 30 afirmaram trabalhar na atividade desde a inauguração do Alto de Santa Rita de Cassia no ano de 2010, o que corresponde a 5 anos de atuação, considerando o recorte temporal desta pesquisa (2010 - 2015). Enquanto os demais, os correspondentes a 20 trabalhadores encontram-se no mercado informal de 1 a 3 anos, com regime de trabalho de 4 a 8 horas diárias. $\mathrm{O}$ trabalho mais intenso é realizado apenas nos finais de semana e feriados, principalmente, aos domingos, pois é o dia de maior fluxo de visitantes.

O próximo questionamento é sobre o rendimento mensal dos trabalhadores autônomos, tem-se que o rendimento mensal da maioria dos trabalhadores é menor que um salário mínimo, cerca de $80 \%$ dos trabalhadores. Os $20 \%$ restantes conseguem uma renda de 1 a 2 salários, sendo que essa variação se dá pela quantidade de mercadoria vendida, significando assim que nem sempre se chega a alcançar esse rendimento.

As pessoas que conseguem ganhar até dois salários se destacam nas suas vendas e adquirem lucro porque vendem produtos diferenciados, como camisetas e bonés, e a produção desse material é feita pelo próprio vendedor. Os demais trabalhadores que recebem menos de um salário mínimo comercializam apenas souvenir (lembrancinhas) fabricados em larga escala, como é o caso de chaveiros, canetas, adesivos, entre outros. Muitas das lembrancinhas não são 
produzidas no município, ou seja, vêm dos grandes centros de distribuição e têm uma disseminação ampla sendo estes encontrados em muitos outros atrativos religiosos do nordeste.

Nesta perspectiva, é notório que apesar do turismo beneficiar com oportunidades de trabalho, ainda não consegue proporcionar no mesmo patamar melhorias nas condições de vida dessas pessoas, pois a atividade informal oferece ao trabalhador apenas um rendimento mensal variável, com o qual consegue com dificuldade suprir algumas necessidades. O mercado informal é caracterizado por um trabalho precário e não legalizado que não estabiliza o trabalhador no mercado, nem ampara o sujeito no tocante a alguma seguridade social, diferente dos legalizados que se encontram protegidos pela legislação trabalhista.

Desta forma, ressalta-se conforme Montenegro (2006) que o circuito inferior da economia urbana13, o circuito inferior da economia é caracterizado por desempenha atividades precária, conter um grande número de pessoas, tendo um trabalho (ocupação) mal remunerado, é uma atividade sem regulamentação e muitas vezes temporária. E nesse contexto, é possível colocar a atividade desenvolvida no principal atrativo do município como integrante do circuito inferior da economia urbana de Santa Cruz.

Vale ressaltar que todos os trabalhadores são do município de Santa Cruz, sendo que nos períodos de alta estação outros trabalhadores que não residem no município surgem, desenvolvendo atividades informais e temporárias ao longo dos meses de festejo e nos períodos de férias.

\section{CONSIDERAÇÕES FINAIS}

O turismo religioso ocasionou algumas transformações no mercado de trabalho no município de Santa Cruz, porém essas foram concentradas no setor de A\&B, de acordo com os resultados demonstrados, uma vez que o referido setor conseguiu crescer $53 \%$ em 5 anos, e a maioria desses empregos são formais. Porém, tendo em vista o investimento de pelo menos 5 milhões de reais nos últimos anos para o turismo, é um retorno insignificante.

No tocante ao setor de meios de hospedagem não se identificou um impulso direto no setor derivado do fluxo de turismo religioso. Ressalta-se que poucas empresas foram beneficiadas, tendo o capital gerado pela atividade acumulado em apenas três empreendimentos, um deles pertencente ao setor hoteleiro que não atribui ao turismo sua expansão no mercado, e sim ao aperfeiçoamento dos serviços e infraestrutura ofertada, diferentemente, dos outros dois que compõem o setor de A\&B.

O setor de restauração ou $A \& B$ foi o que mais gerou empregos formais no município, e atribui-se esse crescimento ao perfil da demanda que o município conseguiu capitar, na sua maioria excursionistas e romeiros, sendo boa parte desse fluxo gerado apenas nos finais de semana.

\footnotetext{
${ }^{13}$ Teoria dos circuitos da economia urbana de autoria do Milton Santos. Essa teoria dividiu a economia urbana em dois circuitos principais o inferior e o superior. O primeiro em relação a economia informal e suburbana. Já a segunda é das instituições empresas formais.
} 
De modo geral, os setores de A\&B e Hotelaria no município possuem juntos cerca de 183 trabalhadores formais, e 12 trabalhadores informais. Sendo assim, esses setores tem uma taxa muito pequena de informalidade $(6,5 \%)$ e prepondera a ocupação legalizada. Já quando a analise parte para o principal atrativo turístico, todas as ocupações geradas naquele ambiente são informais.

Outro ponto relevante é salientar que se considerar apenas os empregos criados após a inserção do turismo religioso tem-se praticamente uma equivalência nos resultados dos setores no que se refere a empregos formais e informais. Ou seja, os setores de A\&B e hotelaria, contratam 64 trabalhadores formais, ao passo que no complexo turístico tem-se no mínimo 50 trabalhadores informais. Assim, somando os 50 trabalhadores informais com 12 dos setores de $\mathrm{A} \& \mathrm{~B}$ e meios de hospedagem também informais, verifica-se que há cerca de 62 trabalhadores informais, contra 64 formais após a implementação do turismo no destino.

A intepretação é que o mercado informal tem acomodado uma parcela da população mais pobre e menos escolarizada, sendo essa oferta de emprego na visão dos trabalhadores uma possibilidade de melhor condição de vida, pois antes do turismo não havia nenhuma oportunidade de emprego que trouxesse geração de renda. Vale esclarecer que o trabalho informal não proporciona um rendimento mensal elevado, sendo caracterizado por condições precárias.

Nesse aspecto o poder público como interventor de políticas públicas e impulsionador do turismo deve atuar na organização dos trabalhadores informais, de maneira a: diminuir as mazelas da informalidade; conscientizar a população da necessidade da buscar por melhores condições de trabalho e organização; bem como participar da gestão responsável e solidária do atrativo do município.

Correlacionando os dados levantados pelo estudo, percebeu-se que o município de Santa Cruz tem alguns obstáculos a vencer em relação ao mercado de trabalho, e ao fluxo de visitantes devido este se concentra apenas nos finais de semana.

Para tanto, tem-se que para enfrentar esse problema de baixa permanência no destino, pode-se criar atrativos complementares a esse fluxo existente, voltados, por exemplo, ao aspecto cultural, lazer e entretenimento.

Além disso, deve haver uma maior preocupação com o tipo de ocupação gerada pelo turismo no município de Santa Cruz, e o poder público deve investir em cursos de capacitação no sentido de melhorar a qualificação da mão de obra, bem como em cursos de organização social desses trabalhadores, pois não é interessante desconsiderar a condição precária do sujeito em meio a um trabalho que não oferece nenhuma seguridade.

Investir em instrumentos de planejamento da atividade com ênfase no tipo de demanda e nas ocupações geradas pelas iniciativas do poder municipal é uma vertente a ser explorada no município, coadunando princípios de seguridade social, saúde e fixidez para os futuros posto de trabalho criado por essa atividade.

Desta forma, a pesquisa foi pertinente por abordar a temática de trabalho e turismo, em uma tentativa de aproximação. Interpreta-se este estudo como um mote para outras investigações, na medida em que acredita-se que há muito a ser estudado no eixo turismo e 
trabalho, especialmente, no que concerne dizer que cada tipo de segmento do turismo e sua demanda especifica vai e/ou pode gerar uma tendência por determinadas ocupações em um destino. Além do mais, outros estudos podem ser realizados na busca por identificar e discutir, por exemplo, qual o segmento do turismo que mais gera empregos formais e informais. Isso demonstra que há de fato muito há pesquisar nesse campo, e colocam essa área como promissoras e enriquecedores quanto aos possíveis questionamentos e possibilidades de teste de hipóteses.

\section{REFERÊNCIAS}

ANJOS, Mayara Abadia Delfino. Trabalho informal e sazonalidade: uma análise na Festa de Nossa Senhora da Abadia em Romaria - MG. Cadernos da FUCAMP. v.10, n.13, p.11-36, 2011.

BARDIN, Laurence. Análise de Conteúdo. Tradutor L'analyse de Contenu. Lisboa. Edições 70, 2004.

BRASIL. Ministério do Turismo. Plano Nacional de Turismo 2007-2010. Secretária de Desenvolvimento de Políticas Públicas. Disponível em: http://www.turismo.gov.br/sites/default/turismo/o_ministerio/publicacoes/downloads_publicac oes/plano_nacional turismo_2007_2010.pdf>. Acesso em 26 de janeiro de 2016.

BRASIL. Ministério do Turismo. Plano Nacional de turismo 2013-2016. Secretária de Desenvolvimento de Políticas Públicas. Disponível em: http://www.turismo.gov.br/images/pdf/plano_nacional_2013.pdf $>$. Acesso em 26 de janeiro de 2016.

CAFIERO, C. O capital: compêndio. São Paulo: Hunterbooks. 2014.

CORIOLANO, L. N. M. T.. Epistemologia da análise do discurso no turismo. Caderno Virtual de Turismo. v. 5. n. 2, 2005.

COSTA, J. H. Trabalhadores de verão: políticas públicas, turismo e emprego no litoral potiguar. Dissertação (mestrado em geografia). Universidade Federal do Rio Grande do Norte. Natal, 2007.

DELANEY, Laurel J. Mulheres empreendedoras revigoram economias. Ejournal USA. Departamento de Estado dos EUA, v. 16 / n. 8, 2012.

IBGE Cidades. Santa Cruz - RN. Disponível em: http://www.cidades.ibge.gov.br/v3/cidades/municipio/2411205. Acesso em 20 de fevereiro, 2017.

KREIN. José Dari WEISHAUPT. Proni Marcelo. Economia informal: aspectos conceituais e teóricos. Brasília: OIT, 2010.

MONTENEGRO. M. R. O circuito inferior da economia urbana na cidade de São Paulo no período da globalização. Dissertação (Mestrado). Universidade de São Paulo. São Paulo, 2006. SANTOS, Milton. O espaço dividido: os dois circuitos da economia urbana dos países subdesenvolvidos. São Paulo: EDUSP, 2004.

SEBRAE. Lei Geral: das micro e pequenas empresas. Brasília, 2012.

Secretaria Municipal de Turismo de Santa Cruz -RN. Inventario da Oferta Turística do Município de Santa Cruz. Prefeitura Municipal de Santa Cruz. 2013. 
SILVA, R. C. Política de regionalização de turismo no interior potiguar: articulação, entraves e efetividade. Dissertação (Mestrado em Turismo). Universidade Federal do Rio Grande do Norte. Natal, 2014.

SOARES, Luís Augusto Severo. Turismo e trabalho informal: um binômio inevitável. Revista Ibero Americana de Estratégia. São Paulo, v. 4, n.1 p. 89-98, 2005.

SOUZA, A. C; OTANI. F. A. P. F. N. TCC: métodos e técnicas. Florianópolis: Visual Books. 2007.

WOLECK, Aimoré. O trabalho, a ocupação e o emprego: uma perspectiva histórica. Instituto Catarinense de Pós-Graduação. Santa Catarina. jan-jun 2002. Disponível em: <http://www.posuniasselvi.com.br/materias/artigos.htm/>Acesso em 29 de Setembro de 2015.

Artigo recebido em: 20/05/2017

Avaliado em: 27/06/2017

Aprovado em: 17/08/2017 